\title{
Nursing care in childcare services: Acantose nigricans as a marker for metabolic risk ${ }^{1}$
}

\author{
Caroline Evelin Nascimento Kluczynik Vieira² \\ Larissa Soares Mariz ${ }^{3}$ \\ Carla Campos Muniz Medeiros ${ }^{4}$ \\ Bertha Cruz Enders ${ }^{5}$ \\ Alexsandro Silva Coura ${ }^{4}$
}

Objective: to analyze the association between the presence of Acantose nigricans and metabolic changes in overweight adolescents, so as to ascertain the relevance of the identification of this marker in the nursing consultation. Method: a cross-sectional study undertaken between April 2009 and April 2010 with 118 adolescents who were service users of the Center for Child Obesity in Campina Grande in the Brazilian State of Paraíba (PB). The presence of Acantose nigricans, and the subjects' anthropometric measurements, were investigated. The following exams were made: insulin, triglycerides, HDL-Cholesterol, Glucose and the homeostatic model of assessment (HOMA-IR). Results: there was association between the presence of Acantose nigricans and participants with insulin resistance $(p=0.008)$, metabolic syndrome $(p=0.031)$, elevated triglycerides $(p=0.045)$ and altered HDL $(p=0.002)$. Conclusions: the suggestion is supported that the detection/identification of Acantose nigricans may be used in the nursing consultation as a tool for identifying overweight adolescents with greater risk of metabolic changes.

Descriptors: Adolescent; Obesity; Acanthosis Nigricans; Nursing Care.

\footnotetext{
${ }^{1}$ Supported by Programa de Incentivo à Pós-Graduação e Pesquisa (PROPESQ/UEPB), process \# 098/2008.

2 Master's student, Universidade Federal do Rio Grande do Norte, Natal, RN, Brazil. Scholarship holder from Coordenação de Aperfeiçoamento de Pessoal de Nível Superior (CAPES).

${ }^{3}$ Doctoral student, Universidade Federal do Rio Grande do Norte, Natal, RN, Brazil. Scholarship holder from Coordenação de Aperfeiçoamento de Pessoal de Nível Superior (CAPES).

${ }^{4} \mathrm{PhD}$, Professor, Departamento de Enfermagem, Universidade Estadual da Paraíba, Campina Grande, PB, Brazil.

${ }^{5} \mathrm{PhD}$, Colaborate Professor, Universidade Federal do Rio Grande do Norte, Natal, RN, Brazil.
}

Corresponding Author:

Caroline Evelin Nascimento Kluczynik Vieira

Av. Senador Salgado Filho, 3000

Bairro: Lagoa Nova

CEP: 59078-900, Natal, RN, Brasil

E-mail: carolinekluczynik@gmail.com
Copyright (c) 2013 Revista Latino-Americana de Enfermagem This is an Open Access article distributed under the terms of the Creative Commons Attribution Non-Commercial License (CC BY-NC).

This license lets others distribute, remix, tweak, and build upon your work non-commercially, and although their new works must also acknowledge you and be non-commercial, they don't have to license their derivative works on the same terms. 


\section{Introduction}

Obesity is a multifactorial condition involving genetic and environmental components. In Brazil, it is considered to be the most relevant nutritional problem in the child age range ${ }^{(1)}$. The accumulation of body fat present in children of school age tends to persist into adolescence, which has physiological and pathological effects in adult life too. For this reason, the characteristics as a risk group and the chances of success for the actions to be implemented cause overweight adolescents to be one of the main target-groups for strategies of prevention and control of overweight and illnesses correlated with it, based on primary healthcare $(\mathrm{PHC})^{(2)}$.

Within the ambit of PHC, the Family Health Strategy (FHS) aims to re-orientate healthcare, previously based on the technical/hospital-centric model, based on the principles of the Unified Health System (SUS). The nurse, as a member of the Family Health Team, carries out, among other activities, the nursing consultation for monitoring children's and adolescents' growth and development - also termed childcare services( ${ }^{(3)}$.

Based on this new care model's implementation, nursing has been incorporating health promotion as an element integral to its area of action(4). In this context, although health promotion is an essential activity in the care of children and adolescents, it is little-based on scientific evidence, being based in classifications through purely anthropometric measurements ${ }^{(2)}$.

The Ministry of Health's Protocol recommends that between 2 and 6 years of age weight and height should be checked and recorded on the system each year. After that, they should be checked and recorded at longer intervals. During adolescence, with the arrival of the growth spurt, it is recommended that this procedure should be undertaken at least once a year. With the increasing emphasis given to triaging obesity, it has been recommended that after the child is two years old one should calculate and mark the Body Mass Index (BMI) on the appropriate graph(3).

According to the analysis of the weight, in line with the World Health Organization's (WHO) growth curve, in the event of a result which is increasing and over the $97^{\text {th }}$ percentile, the nurse's conduct should be based on ascertaining the existence of mistakes in feeding, advising the mother to offer more appropriate food, through the diet suggested by the Manual itself, in addition to checking and encouraging regular physical activity. It is the nurse's role to know what normal adolescent development is (and variations on this), offering advice to the family and, if necessary, organizing referrals for diagnosis and intervention as early as possible ${ }^{(3)}$.

In Brazil, traditionally, the service users at high risk of diabetes are identified based on family history and monitoring of weight ${ }^{(5)}$. One can, however, adopt as another indicator Acantose nigricans (AN), which is characterized by dark-brown velvety papilomatous dermatitis, with hyperkeratotic plaques in regions such as the neck (93-99\%) and the axilla areas (73\%), followed, with a lower frequency, by the fingers and toes ${ }^{(6-8)}$. Although $\mathrm{AN}$ is more commonly associated with obesity and insulin resistance (IR), studies have suggested that its presence may also indicate type 2 diabetes, metabolic syndrome (MS), and polycystic ovary syndrome ${ }^{(9)}$.

The study is justified bearing in mind that obesity in adolescence is included in the National Agenda of Priorities in Health Research, and that overweight is associated with risk factors for health(10), as well as because the identification of AN as a risk marker is still not found in the nursing childcare services consultation ${ }^{(3)}$, it being important to strengthen the relevance of using this marker by means of a study of its association with metabolic changes. However, its inclusion could help in the classification of risk among overweight adolescents, as $A N$ is an easily-identifiable clinical characteristic with no financial onus for the investigating body, and is applicable in primary healthcare ${ }^{(8)}$. It also stands out that for the primary prevention of nutritional problems, one needs methods which nurses and healthcare professionals can use easily(11).

Based on the assumptions that $A N$ is related to metabolic problems, and that the early recognition of this dermatosis is essential for the prevention and controlling the progression of these health issues ${ }^{(9)}$ the present study sought to ascertain the association between the presence of AN and metabolic changes in overweight children and adolescents, so as to verify the relevance of including the identification of this marker in the nursing consultation.

\section{Method}

This is a cross-sectional study with a quantitative approach, undertaken in the Center for Child Obesity (COI) in Campina Grande/Paraíba (PB), Brazil. The COI includes researchers and a multi-professional team, the latter made up of nurses, endocrinologists, nutritionists, a psychologist, a social worker and a fitness coach. It 
was set up three years ago and is a center of excellence in the treatment of obese children and adolescents in Campina Grande/PB.

This study is itself part of a broader study titled: "Prevalence and cardio-metabolic risk factors among overweight children and adolescents". In this research, the selection of the participants took place through publicising the investigation in the Primary Healthcare Units in the Municipality of Campina Grande/PB, this being done by the Municipal Health Department. The sample calculation was undertaken taking into account the city's child/adolescent population, as recorded in December 2008 on the Primary Care Information System (SIAB), totalling 65,890 children and adolescents aged between 1 and $19^{(5)}$. For calculating patients who had been seen at the COI, initially the prevalence of overweight and obesity of $25 \%$ was considered(12) followed, later, by MS of $42 \%{ }^{(13)}$. This encompassed 202 overweight or obese individuals aged between 2 and 18 years old, referred from Primary Care. The exclusion criteria were: the presence of diabetes and the use of medications which alter blood pressure, glucose or the lipid metabolism. Of these 202 overweight adolescents and children, only the adolescents aged between 10 and 19 years old were included in the present study's analyses, making up a sample of 118 individuals.

Data collection occurred between April 2009 and April 2010. The triage was carried out by the nurses of the COI, who undertook a thorough clinical examination seeking abnormalities which are characteristic in overweight patients, among which is AN on the posterior part of the neck, in the armpits and between the fingers and toes, anthropometric measurements also being made and laboratory tests being scheduled.

The anthropometric variables of weight and height were collected in duplicate, based on the criteria of standardization recommended by the WHO. The mean of the two measurements was considered. For obtaining the weight, a digital platform scale (Welmy ${ }^{\circledR}$ brand) was used, with the children and adolescents shoeless, in light clothes, and positioned in the center of the scale's platform. The height was measured using a stadiometer (Tonelli ${ }^{\circledR}$ brand) with the participants shoeless, in an orthostatic position, their arms by their sides, their feet together, their knees straight, and their heads in the horizontal Frankfurt plane, after a deep breath(14).

The abdominal circumference (AC) was evaluated with an in-elastic tape measure with a precision of 0.5 $\mathrm{cm}$, at the middle point between the upper edge of the iliac crest and the lower costal margin, with the patients standing, in their underwear with their arms by their sides and in the expiratory phase of respiration. Values over the $90^{\text {th }}$ percentile were considered as increased, which represents the maximum limit of $88 \mathrm{~cm}$ for the girls and $102 \mathrm{~cm}$ for the boys ${ }^{(15)}$.

Blood pressure was checked at three points, with rest intervals of approximately 2 minutes, in line with the method established in the $\mathrm{V}$ Brazilian Guidelines on Arterial Hypertension, using a Tycos brand mercury sphygmomanometer, using appropriately-sized cuffs. The means of the last two measurements were considered as the systolic and diastolic pressures ${ }^{(16)}$.

For the classification of the nutritional status, the Body Mass Index (BMI) was calculated, in line with recommendations from the Centers of Disease Control and Prevention (CDC). The percentiles were used, with the following categories: overweight $(85 \geq \mathrm{BMI}<95)$, obesity $(95 \geq B M I<97)$ and serious obesity $(B M I \geq 97)^{(17)}$.

The basal blood samples were obtained from fasting patients, in order to measure the levels of insulin, lipids, glycemia, triglycerides and HDL-c. All the patients had been previously instructed to fast for a minimum of 10 hours prior to the taking of the blood sample. The tests were undertaken in the Clinical Analysis Laboratory of the State University of Paraíba (LAC/UEPB).

The analysis of insulin was calculated and measured using the INSULIN-CT method of radioimmunoassay of CIS Bio International ${ }^{\circledR}$, using an Abbott $^{\circledR}$ gamma counter (intra-assay coefficient of variation $2.6 \%$ ) in a tertiarized laboratory with a seal of quality. The authors considered hyperinsulinism to be the presence of basal insulin > $143.5 \mathrm{pmol} / \mathrm{liter}$ and $>430.5 \mathrm{pmol} /$ liter after the glucose tolerance test, in line with the WHO criteria, or insulin $>86.1 \mathrm{pmol} /$ liter with $\mathrm{mmol}$ of glucose $<3.3 /$ liter.

The IR data was based on the homeostatic model of assessment (HOMA), calculated as the product of the level of fasting plasmatic insulin (in micro-units per milliliter) and the level of fasting blood glucose levels (in millimoles per liter), divided by 22.5 . Levels were ordinarily gamma $0.3-10$; where the scores were $>3.5$, it was taken that insulin resistance was present; where the score was $<3.5$, that the person was sensitive to insulin.

The HDL-c, the triglycerides and the glycemia were evaluated by the enzymatic colorimetric method, on automatic equipment (BioSystems Model 310), in line with the recommendations of the maker of the Labtest ${ }^{\circledR}$ kit, in the LAC/UEPB.

The data was presented using proportions, means, the Pearson Chi-Squared test and standard-deviation 
(SD). The one-way ANOVA was used for comparison of the means. All the analyses were bicaudal and undertaken with version 19.0 of the Statistical Package for the Social Sciences (SPSS) program, the level of significance being considered to be $5 \%$.

The parents gave their assent, signing the Terms of Free and Informed Consent (TFIC), obtained before the initial diagnostic tests were carried out. The study protocol had been previously analyzed and approved by the State University of Paraíba's Research Ethics Committee under no 0040.0.133.000-08, in accordance with Resolution 196/96 of the National Health Council.

\section{Results}

Table 1 presents the participants' characteristics: sex, race, nutritional status, presence of $A N$ and IR. Among the participants one may observe a greater frequency of females $(71.2 \%)$, non-whites $(66.1 \%)$, and the seriouslyobese (56.8\%). Analyzing the prevalence of AN and IR, the values of $63.6 \%$ and $53.4 \%$ were identified, respectively.

Next, the association of the social and clinical variables with AN was analyzed, significance being observed in the presence of AN among the participants with IR $(p=0.008)$, MS $(p=0.031)$, triglycerides $(p=0.045)$ and altered HDL $(p=0.002)$. It is also emphasized that, although there was no association, the frequency of AN was higher in the females, the nonwhites, and those with serious obesity and high blood pressure (Table 2 ).
Table 1 - Frequency of sex, race, nutritional status, Acantose nigricans and insulin resistance in overweight adolescents. COI, Campina Grande, PB, Brazil, 20092010. $(n=118)$

\begin{tabular}{lcc}
\hline \multicolumn{1}{c}{ Characteristic } & $\mathbf{n}$ & $\%$ \\
\hline Sex & 34 & 28.8 \\
$\quad$ Male & 84 & 71.2 \\
$\quad$ Female & & \\
Race & 40 & 33.9 \\
$\quad$ White & 78 & 66.1 \\
$\quad$ Non-white & & \\
Nutritional status & 25 & 21.2 \\
Overweight $(85 \geq \mathrm{BMI}<95)$ & 26 & 22.0 \\
$\quad$ Obesity $(95 \geq \mathrm{BMI}<97)$ & 67 & 56.8 \\
$\quad$ Serious obesity $(\mathrm{BMI} \geq 97)$ & & \\
Acantose nigricans & 75 & 63.6 \\
$\quad$ Present & 43 & 36.4 \\
Absent & & \\
Insulin resistance & 63 & 53.4 \\
Present & 55 & 46.6 \\
$\quad$ Absent
\end{tabular}

In relation to the prevalence ratio, it is the case that the people with IR and MS have risks which are 3.53 and 4.14 times higher, respectively, of presenting AN, when compared with individuals without these metabolic changes. Similarly, the participants with altered triglycerides and $\mathrm{HDL}$ have risks 4.42 and 2.13 times higher, respectively, of having $\mathrm{AN}$, when compared to the participants within normal scores.

In analyzing the mean values of the clinical variables associated with the presence or absence of $\mathrm{AN}$, an association was observed between $\mathrm{AN}$ and insulin $(p=0.056)$ and triglycerides $(p=0.038)$, as these were significantly higher among persons with AN. Similarly, HDL $(p=0.001)$ was associated with $A N$, the persons with AN having levels below the normal levels (Table 3 ).

Table 2 - Frequency, significance, prevalence ratio and confidence interval of social and clinical variables, related to the presence of Acantose nigricans in overweight adolescents. COI, Campina Grande, PB, Brazil, 2009-2010

\begin{tabular}{|c|c|c|c|c|}
\hline \multirow{2}{*}{ Variables } & \multicolumn{2}{|c|}{ Acantose nigricans (\%) } & \multirow{2}{*}{$p$} & \multirow{2}{*}{$\begin{array}{l}\text { Prevalence Ratio } \\
\text { Confidence Interval }\end{array}$} \\
\hline & Present & Absent & & \\
\hline Sex & & & 0.890 & \\
\hline Male & 29.3 & 27.9 & & \\
\hline Female & 70.7 & 72.1 & & \\
\hline Race & & & 0.074 & \\
\hline Whites & 28.0 & 44.2 & & \\
\hline Non-whites & 72.0 & 55.8 & & \\
\hline
\end{tabular}


Table 2 - (continuation)

\begin{tabular}{|c|c|c|c|c|}
\hline \multirow{2}{*}{ Variables } & \multicolumn{2}{|c|}{ Acantose nigricans (\%) } & \multirow{2}{*}{$p$} & \multirow{2}{*}{$\begin{array}{l}\text { Prevalence Ratio } \\
\text { Confidence Interval }\end{array}$} \\
\hline & Present & Absent & & \\
\hline Nutritional status & & & 0.185 & \\
\hline Serious obesity $\left(\mathrm{BMI}^{*} \geq 97\right)$ & 61.3 & 48.8 & & \\
\hline Obesity $(95 \geq \mathrm{BMI}<97)$ & 38.7 & 51.2 & & \\
\hline Insulin resistance & & & 0.008 & \\
\hline Present & 62.7 & & & 3.53 \\
\hline Absent & 37.3 & & & $(1.63-7.67)$ \\
\hline Metabolic Syndrome & & & 0.031 & \\
\hline Present & 77.0 & & & 4.14 \\
\hline Absent & 23.0 & & & $(1.84-9.34)$ \\
\hline Triglycerides & & & 0.045 & \\
\hline Altered & 53.3 & & & 4.42 \\
\hline Normal & 46.7 & & & $(1.98-9.91)$ \\
\hline $\mathrm{HDL}^{\dagger}$ & & & 0.002 & \\
\hline Altered & 90.7 & & & 2.13 \\
\hline Normal & 9.3 & & & $(0.78-5.83)$ \\
\hline Blood pressure & & & 0.347 & \\
\hline High & 73.3 & 65.1 & & \\
\hline Normal & 26.7 & 34.9 & & \\
\hline
\end{tabular}

*BMI = body mass index

$+\mathrm{HDL}=$ high density lipoprotein

Table 3 - Mean values and standard deviation of the clinical variables, according to the presence or absence of Acantose nigricans in overweight adolescents. COI, Campina Grande, PB, Brazil, 2009-2010

\begin{tabular}{|c|c|c|c|c|c|}
\hline \multirow{2}{*}{ Variables } & \multicolumn{3}{|c|}{ Acantose nigricans (\%) } & \multirow[b]{2}{*}{$\mathrm{Cl} 95 \%$} & \multirow{2}{*}{$p$} \\
\hline & Present Mean ( \pm ) & $\mathrm{Cl} 95 \%$ & Absent Mean ( \pm ) & & \\
\hline Body mass index & $29.4( \pm 4.8)$ & $28.3-30.5$ & $27.9( \pm 3.6)$ & $26.8-29.1$ & 0.086 \\
\hline Insulin (mg/dl) & $15.4( \pm 9.3)$ & 13.3-17.6 & $12.2( \pm 6.9)$ & $10.1-14.4$ & 0.056 \\
\hline $\mathrm{HDL}^{*}(\mathrm{mg} / \mathrm{dl})$ & $35.7( \pm 6.7)$ & $34.1-37.2$ & $41.7( \pm 12.5)$ & $37.8-45.6$ & 0.001 \\
\hline Triglycerides & $145.9( \pm 75.8)$ & $128.4-163.3$ & $117.3( \pm 62.4)$ & $98.1-136.5$ & 0.038 \\
\hline Glycemia & $82.7( \pm 7.5)$ & $81.0-84.4$ & $80.5( \pm 7.3)$ & $78.2-82.8$ & 0.126 \\
\hline Diastolic blood pressure $(\mathrm{mm} / \mathrm{Hg})$ & $74.3( \pm 10.5)$ & $71.95-76.79$ & $73.6( \pm 8.0)$ & $71.1-76.0$ & 0.679 \\
\hline Systolic blood pressure $(\mathrm{mm} / \mathrm{Hg})$ & $111.5( \pm 11.8)$ & 108.8-114.2 & $110.9( \pm 11.1)$ & $107.5-114.3$ & 0.772 \\
\hline Abdominal Circumference (cm) & $91.0( \pm 11.8)$ & $88.3-93.7$ & $89.8( \pm 11.6)$ & $86.2-93.4$ & 0.591 \\
\hline
\end{tabular}

*HDL = high density lipoprotein

\section{Discussion}

A considerable proportion of the Brazilian population aged under 18 is over the weight recommended for the height and age. Among these individuals, those at greater cardio-metabolic risk must be identified, so that they may be referred to the appropriate service as early as possible ${ }^{(3)}$. Studies suggest that the presence of $A N$ is a risk indicator for IR, type 2 diabetes and MS, principally when associated with obesity ${ }^{(6-8)}$. Further studies are necessary, however, to determine whether the presence of this dermatosis is a sensitive indicator of the individual's metabolic status since

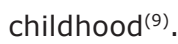


In the present study, the majority of the participants were female, non-white, seriously obese, and with AN and IR. This data is worrying, as obesity in this age range tends to persist into adulthood and is associated with the appearance of cardio-vascular and metabolic illnesses. When the individual is seriously obese, the prognosis is even worse ${ }^{(10)}$. According to the Manual "Children's Health: Monitoring Child Growth and Development", on using the WHO growth curve and finding a rising result, over the $97^{\text {th }}$ percentile, it is the duty of the nurse to advise the family and the child or adolescent. If there is the suspicion of metabolic risk, the patient should be referred, so as to give continuity in secondary care, through specialized assistance, without breaking the link with primary care(3).

In the Brazilian population, overweight and obesity are considered to be the most relevant nutritional problems in the child age range, with a significant increase in recent decades(1). In the sample in question, an association was observed between excess weight and the presence of probable metabolic disorder, as 75\% had AN, and $63 \%$ IR. A similar result was found in a study undertaken with overweight children and adolescents in the University Hospital of Campinas, in which $58 \%$ of the sample had $\mathrm{AN}^{(18)}$

The association between the clinical variables (altered IR, MS, triglycerides and $\mathrm{HDL}$ ) and the presence of AN ascertained in this study corroborates a literature review, which concluded that the presence of AN is more associated with obesity and IR, but that it can also indicate other metabolic disorders, such as type 2 diabetes and $\mathrm{MS}^{(9)}$

Studies have shown a tendency for the association of cervical AN with higher risk of metabolic alterations from adolescence onwards( ${ }^{(8)}$. In the present study, those with AN had a higher risk for IR and MS, as well as a higher risk for alteration in the levels of triglycerides and HDL. Research undertaken in the United States, which assessed individuals from 7 to 65 years old, revealed that the frequency of AN among children and adolescents is considerable (42.6\%), it being the indicator for metabolic disorder which, from childhood onwards, should be the best investigated. The results revealed that in adolescence the clinical identification of AN becomes as frequent as in adult individuals and is directly related to metabolic changes, principally abnormal insulin activity ${ }^{(8)}$.

AN was associated with high means of insulin and triglycerides, and with mean values for HDL which are below normal levels. Another study, undertaken with
North-American adolescents, concluded that obesity alone is not responsible for the presence of AN: rather, it is hyperinsulinemia, which allows its development by increasing the circulating levels of insulin, principally in the receptors which are also responsible for the proliferation of epidermis, with a predilection for cells in hypoactivity, such as in the folds of the body ${ }^{(6)}$. This mechanism explains the high frequency of $A N$ in individuals who also present IR.

In this context, AN may be considered as a metabolic risk marker in the nursing consultation, permitting early identification of complications in the health situation of overweight or obese adolescents. The nurse must act as a mediator between the health service and the family. With nutritional advice and monitoring, the expectation is that children and adolescents may change their living habits (diet and undertaking of physical activities), even if they are unable to comply with all the guidance. It is very important to praise even the smallest changes, such as, for example, swapping junk food for fruit in the packed lunch for school, in order to encourage them to improve. For this approach, short-term goals must be defined to encourage the adolescents, enabling them to manage to follow the advice.

In this context, the treatment is long and the prevention of metabolic disorders a public health priority the change can start in the nursing consultations in the health centers ${ }^{(19)}$, as well as through health education actions in the schools ${ }^{(20)}$. It is stressed, however, that in spite of the nurse being fundamental in this process, it is necessary for the actions to be multi- and inter-disciplinary, through teamwork, in which other professionals, such as nutritionists and the psychologists, may also be mediators.

Finally, it stands out that the evaluation of overweight adolescents was considered a limitation of the present study, as it did not make it possible to verify these variables' behavior in persons within normal limits. Nevertheless, the profile found shows that the presence of AN in overweight individuals has a known association with metabolic alterations, from adolescence onwards. This research's peculiarity is the age range of the group studied, which differs from the majority of the works carried out in this issue.

\section{Conclusion}

The Brazilian setting reflects a worldwide epidemic, as overweight and obesity are the most relevant nutritional problems in the child age range. For this 
reason, the early identification of patients at high risk of developing cardio-metabolic disorders is very important, so that, by adopting a more appropriate life style from childhood onwards, this health risk may be prevented.

Although greater clarification will only be possible through longitudinal studies, this study's contribution is to indicate that the presence of AN is shown to be a good marker for identifying adolescents with IR, MS, and alterations in the levels of triglycerides, insulin and $\mathrm{HDL}-\mathrm{C}$, allowing earlier identification of those who are at higher risk of developing metabolic disorder. Although this condition does not present association with the other components of MS, the mean values of BMI, fasting glycemia, AC and systolic and diastolic blood pressure were higher among those who had AN.

In the light of these results, it is strongly suggested that AN should be added to the nursing consultation, as a sign for identifying overweight adolescents at higher risk of metabolic changes, as it falls to the nurse, in Primary Care, to identify individuals who are overweight, to advise them, and in the case of greater metabolic risk, to refer them to the appropriate service. For that, the need is emphasized for training for the nurses, directed at the identification of $\mathrm{AN}$, as this sign is associated with the most adverse metabolic profile. In this context, it is recommended that such training should be administered with support from specialists who work in other institutions, such as researchers linked with universities, through extension projects.

\section{References}

1. Ministério da Saúde (BR). Sistema de Informação da Atenção Básica (SIAB). Brasília: Fundação Nacional de Saúde; 2010.

2. Rodrigues PA, Marques MH, Chaves MGAM, Souza

CF, Carvalho MF. Prevalência e fatores associados a sobrepeso e obesidade em escolares da rede pública. Ciênc Saúde Coletiva. 2011;16(suppl 1):1581-8.

3. Ministério da Saúde (BR). Saúde da Criança: Acompanhamento do Crescimento e Desenvolvimento Infantil. Brasília: Ministério da Saúde; 2002.

4. Lopes MSV, Saraiva KRO, Fernandes AFC, Ximenes LB. Análise do conceito de promoção da saúde. Texto Contexto Enferm. 2010;19(3):461-8.

5. Drobac S, Brickman W, Smith T, Binns HJ. Evaluation of a type 2 diabetes screening protocol in an urban pediatric clinic. Pediatrics. 2004;114:141-8.

6. Lee HW, Suh HS, Choi JC, Lee MW, Choi JH, Moon KC, et al. Hyperkeratosis of the nipple and areola as a sign of malignant acanthosis nigricans. Clin Exp Dermatol. 2005;30:721-2.

7. Ghosh S, Roychowdhury B, Mukhopadhyay S, Chowdhury S. Clearence of acanthosis nigricans associated with insulinoma following surgical resection. Q J Med. 2008;101:899-900.

8. Kong AS, Williams RL, Rhyne R, Urias-Sandoval V, Cardinali G, Weller NF, et al. Acanthosis nigricans: high prevalence and association with diabetes in a practicebased research network consortium - a Primary care Multi-Ethnic Network (PRIME Net) study. J Am Board Fam Med. 2010;23(4):476-85.

9. Higgins ST, Fremark M, Prose NS. Acanthosis nigricans: a practical approach to evaluation and management. Dermatol Online J. 2008;14(9):2.

10. Rico RC, Rico RG, Almeida CAN, Ramos APP. Estudo comparativo de fatores de risco em crianças e adolescentes com diagnóstico antropométrico de sobrepeso ou obesidade. Rev Paul Pediatr. 2010;28(4):320-5.

11. Cocetti M, Castilho SD, Barros AA Filho. Dobras cutâneas e bioimpedância elétrica perna-perna na avaliação da composição corporal de crianças. Rev Nutr. jul-ago 2009;22(4):527-36.

12. Silva RC, Miranda WL, Chacra AR, Dib AS. Metabolic syndrome and insulin resistance in normal glucose tolerant Brazilian adolescents with family history of type 2 diabetes. Diabetes Care. 2005;28:716-8.

13. Buff CG, Ramos E, Souza FIS, Sarni ROS. Frequência de síndrome metabólica em crianças e adolescentes com sobrepeso e obesidade. Rev Paul Pediatr. 2007;25(3):221-6.

14. World Health Organization. Physical Status: the study and interpretation of anthropometry. WHO Technical Report Series. Geneva: WHO; 1995.

15. Third Report of the National Cholesterol Education Program (NCEP). Expert panel on detection, evaluation, and treatment of high blood cholesterol in adults (adult treatment panel III) final report. Circulation. 2002;106:3143-421.

16. Sociedade Brasileira de Cardiologia. V Diretrizes Brasileiras de Hipertensão Arterial. São Paulo: SBC; 2006.

17. Centers of Disease Control and Prevention (USA). Table for calculated body mass index values for selected highs and weights for ages 2 to 20 years. Developed by the National Center for Health Statistic in collaboration with the National Center for Chronic Disease Prevention and Health Promotion, 2000. [Internet]. 2001 [acesso 30 jun 2012]. Disponível em: http://www.cdc.gov/ growthcharts. 
18. Zambon PM, Antonio MA, Mendes RT, Barros AA Filho. Características clínicas e laboratoriais de crianças e adolescentes obesos. Rev Paul Pediatr. 2007;25(1):27-32.

19. Fernandes RA, Vargas AS. O cuidado de enfermagem na obesidade infantil. Rev Meio Amb Saúde. 2007;2(1):273-81.

20. Macêdo SF, Araújo MFM, Marinho NPB, Lima ACS, Freitas RWF, Damasceno MMC. Risk Factors for Type 2 Diabetes Mellitus in Children. Rev. Latino-Am. Enfermagem. 2010; 18(5):936-42. 